\title{
MR
}

\section{Multidrug resistance gene (MDR1) polymorphisms may not be directly associated with response to imatinib in chronic myeloid leukemia}

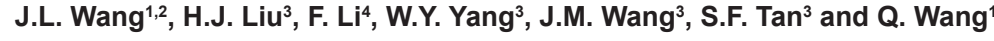 \\ 1Department of Clinical Laboratory, Nanfang Hospital, Southern Medical University, \\ Guangzhou, China \\ 'Linyi People's Hospital of Shandong Province, Linyi, China \\ ${ }^{3}$ Department of Urology Linyi People's Hospital of Shandong Province, Linyi, China \\ ${ }^{4}$ Personnel Department, Linyi People's Hospital of Shandong Province, Linyi, China \\ Corresponding author: Q. Wang \\ E-mail: wangqian632@163.com
}

Genet. Mol. Res. 14 (4): 14967-14978 (2015)

Received April 14, 2015

Accepted July 14, 2015

Published November 24, 2015

DOI http://dx.doi.org/10.4238/2015.November.24.4

ABSTRACT. Our study aimed to investigate the association between multidrug resistance (MDR1) gene polymorphisms and the response to imatinib (IM) in chronic myeloid leukemia (CML). An electronic databases in PubMed, Cochrane Library, Wanfang, China National Knowledge Infrastructure, and VIP were searched using combinations of keywords relating to MDR1 polymorphisms and the response to IM in CML. Studies retrieved from database searches were screened using stringent inclusion and exclusion criteria. The Comprehensive Meta-analysis 2.0 software was utilized for all statistical analyses. In total, 186 studies were initially retrieved, and 10 studies, involving $987 \mathrm{CML}$ patients, were eventually included in this meta-analysis. Results of our study revealed no significant associations between MDR1 rs1045642, rs1128503, and rs2032582 polymorphisms and major molecular response and complete molecular 
response in CML patients. Significant differences were observed in the genotype frequencies of MDR1 rs1128503 under homozygous, heterozygous, and recessive models, between CML patients sensitive and resistant to IM. A significant difference in genotype frequencies of MDR1 rs2032582 was also observed under allele, homozygous, heterozygous, and recessive models between $\mathrm{CML}$ patients sensitive and resistant to IM. In conclusion, based on our meta-analysis, the MDR1 polymorphisms, rs1045642, rs1128503, and rs2032582, are not directly correlated with the curative effect of IM treatment of CML patients.

Key words: Chronic myeloid leukemia; Multidrug resistance gene; Imatinib; Polymorphisms; Major molecular response; Complete molecular response

\section{INTRODUCTION}

Chronic myeloid leukemia $(\mathrm{CML})$ is a clonal myeloproliferative neoplasm characterized by excessive accumulation of apparently normal myeloid cells, leading to the expansion of hematopoietic cells carrying the oncogenic break point cluster region-abelson (BCR-ABL) fusion gene that encodes the active BCR-ABL protein tyrosine kinase (Della Peruta et al., 2010; Kantarjian et al., 2011). CML occurs at an incidence rate of 1-2 cases per 100,000 adults and accounts for approximately $15 \%$ of newly diagnosed cases of leukemia in adults, with an estimated 5920 new cases and 610 deaths in the US in 2013 (Jabbour and Kantarjian, 2012; Soverini et al., 2014). In the West, the median age of onset is 50-60 years, which reflects the average age of the population (Perrotti et al., 2010). Central to the pathogenesis of CML is the fusion of the ABL gene on chromosome 9 with the BCR gene on chromosome 22, which results in expression of the oncoprotein, BCR-ABL (Jabbour and Kantarjian, 2012). CML develops from a hematopoietic stem cell and displays multilineage differentiation potential (Hurtz et al., 2011). The natural history of $C M L$ comprises 3 distinct phases: initial chronic phase $(C P)$, intermediate accelerated phase (AP), and terminal blast phase (BP) (Pavey et al., 2012). Nearly $90 \%$ of patients present with $\mathrm{CML}$ in $\mathrm{CP}$, which is a relatively slowly progressing stage featured by well-differentiated leukemic cells (Jabbour et al., 2011). Tyrosine kinase inhibitor therapy targeting BCR-ABL1 kinase is extremely effective against CML (O'Hare et al., 2012).

Imatinib (IM) is a selective small molecule inhibitor of tyrosine kinase activity of the BCR$A B L$ fusion protein that is prescribed to treat gastrointestinal stromal tumors and is now a frontline therapy for CML (Ni et al., 2011; Seong et al., 2013). In IM therapy, IM inhibits BCR-ABL1 from phosphorylating downstream target proteins and blocks the signaling cascade necessary for CML development (Vivona et al., 2014). IM has significantly improved the long-term survival rates and clinical responses in CML patients, but suboptimal responses and treatment failures have also been observed (Jabbour et al., 2009; Seong et al., 2013). Several studies have suggested that IM is a substrate for membrane transporters, such as the multidrug resistance protein 1 (MDR1), which is also known as the ATP-binding cassette subfamily B member 1 (ABCB1) or P-glycoprotein (P-gp) (Bilgi et al., 2010; Giannoudis et al., 2014). MDR1 is located on the 7q21.1 chromosome and encodes a glycoprotein of $170 \mathrm{kDa}$ (P-gp and MDR1) (Bodor et al., 2005). Recently, genetic variations of MDR1, including more than 50 polymorphisms, have been extensively studied, and among these polymorphisms, rs1128503, rs1045642, and rs2032582 are the most widely studied 
polymorphisms (Kurzawski et al., 2006). Although specific genotypes of genes involved in IM bioavailability seem to affect the function of the relative protein, there is still controversy regarding the role of MDR1 genetic variations in the response to IM therapy in patients with CML (Maffioli et al., 2011). While some studies have suggested that MDR1 genetic variations influence response to IM therapy in CML patients (Deenik et al., 2010; Seong et al., 2013; Vivona et al., 2012, 2014), another study failed to find this correlation (Au et al., 2014). Moreover, few studies have focused on MDR1 and its relation with the clinical features or treatment responses in CML (Vasconcelos et al., 2011). Hence, we conducted a meta-analysis to further investigate the associations between MDR1 polymorphisms and response to IM in patients with CML.

\section{MATERIAL AND METHODS}

\section{Literature search strategy}

We performed a comprehensive literature search for relevant studies publishedprior to October 2014 using the electronic databases of PubMed, Cochrane Library, Wanfang, China National Knowledge Infrastructure, and VIP. The following terms were used in the searches: multidrug resistance 1, MDR1, $A B C B 1$, multidrug resistant gene, chronic myelocytic leukemia, imatinib, glivec, imatinib mesylate, imatinib methanesulfonate, and imatinib methanesulfonate.

\section{Selection criteria}

Eligible studies met the following inclusion criteria: 1) the study type had to be a casecontrol, 2) the study subjects had to be pathology-verified CML patients, 3) patients were treated with IM (300-800 mg/day), 4) the end outcomes included major molecular response (MMR), complete molecular response (CMR), and frequencies of MDR1 gene. The exclusion criteria were as follows: 1) the study type was a review, letter or non-human study, 2) the study was unrelated to our research topics, 3) lack of data integrity, 4) it was non-English or non-Chinese study, 5) papers repeatedly published by the same authors.

\section{Data extraction and quality evaluation}

Two investigators independently carried out data extraction based on a predefined form. The main information extracted included: first author, publication time, country, language, ethnicity, therapy, number of patients, age, gender, treatment time, and genotyping method. Any disputes during the data extraction process were resolved through discussion with the multiple investigators. The quality evaluation of studies included was performed by more than two investigators using Methodological Index for Non-Randomized Studies (MINORS) criteria (Slim et al., 2003). MINORS is a validated scoring tool for non-randomized studies including a 12-item assessment with each item being scored from 0 to 2 . Items 1 to 8 were specified for non-comparative studies with an ideal score of 16 points and items 1 to 12 were applicable for comparative studies with an ideal score of 24 points. The specific 12 criteria were shown as follow: clearly stated aim (MINORS01), inclusion of consecutive patients (MINORS02), prospective collection of data (MINORS03), endpoints appropriate for aim (MINORS04), unbiased assessment of endpoint (MINORS05), appropriate follow-up period (MINORS06), loss to follow-up <5\% (MINORS07), prospective calculation of study 
size (MINORS08), an adequate control group (MINORS09), contemporary groups (MINORS10), baseline equivalence of groups (MINORS11), adequate statistical analyses (MINORS12).

\section{Statistical methods}

All the meta-analyses were performed using Comprehensive Meta-analysis version 2 (Biostat Inc., Englewood, NJ, USA). To evaluate studies investigating the association between MDR1 polymorphisms and response to IM in CML patients, the odds ratio (OR) with $95 \%$ confidence interval $(\mathrm{Cl})$ was used. $A \mathrm{Z}$ test was employed to detect the significance of overall effect size (Chen et al., 2012), and forest plots were drawn to display values of $\mathrm{OR}$ at $95 \% \mathrm{Cl}$ for the case and control groups. Heterogeneity among studies was evaluated by the Cochran's Q-statistic $(a \mathrm{P}<0.05$ was considered having evident heterogeneity) and $l^{2}$ test, which is the percentage of total variation across studies ranging from 0 to $100 \%$ (Peters et al., 2006; Jackson et al., 2012). A random-effect model was applied if there was significant heterogeneity $\left(P<0.05\right.$ or $\left.l^{2}>50 \%\right)$, otherwise, a fixed-effect model was employed (Zintzaras and loannidis, 2005). One-way sensitivity analysis was performed to evaluate whether the removal of one single study would have influences on the overall outcomes. The publication bias, which assesses the reliability of the results, was evaluated by funnel plot, Egger test (Egger et al., 1997; Sterne and Egger, 2001), and classic fail-safe N (Wikstrom et al., 2009). All tests were two-sided, and $\mathrm{P}<0.05$ indicated a significant difference.

\section{RESULTS}

\section{Literature search results and baseline characteristics of the studies included}

In total, 186 articles were initially identified. After excluding duplicates $(\mathrm{N}=8)$, animal studies $(N=5)$, letters, reviews, meta-analyses $(N=4)$, and non-English or non-Chinese studies $(\mathrm{N}=10), 159$ papers remained. A further screening process excluded studies that were not casecontrol $(\mathrm{N}=30)$, studies not relevant to IM $(\mathrm{N}=48)$, studies unrelated to $A B C B 1$ or $M D R 1(\mathrm{~N}=41)$, weakly correlated data in studies $(N=14)$, insufficient information in studies $(N=16)$. At the end of the selection process, a total of 10 articles, published between 2008 and 2014, and including 987 patients with CML, were finally selected for meta-analysis (Dulucq et al., 2008; Deenik et al., 2010; Kim et al., 2010; Marin et al., 2010; Takahashi et al., 2010; Ni et al., 2011; Elghannam et al., 2013; Seong et al., 2013; Au et al., 2014; Vivona et al., 2014). Of the 10 studies, 1 was performed in Africans, 4 were performed in Asians, and 5 in Caucasians. All patients enrolled were treated with IM (300-800 mg/day). Genotyping methods used were qPCR, PCR-RFLP, RT-PCR, MassARRAY, or TaqMan Assay. The baseline characteristics and the quality evaluation of the studies included are displayed in Table 1 and Figure 1, respectively.

\section{Association between MMR to IM in CML patients and MDR1 polymorphisms}

A test revealed that no heterogeneity existed across the gene frequencies of CML patients with MMR and non-MMR under allele, dominant, and heterozygous models (allele model: $\mathrm{P}=0.15$, $l^{2}=47.8 \%$, dominant model: $\mathrm{P}=0.332, l^{2}=10.5 \%$, heterozygous model: $\mathrm{P}=0.15, l^{2}=49.5 \%$ ); therefore, a fixed-effect model was used. However, there was heterogeneity under homozygous and recessive models (homozygous model: $\mathrm{P}=0.009, I^{2}=51.4 \%$; recessive model: $\mathrm{P}=0.008, I^{2}$ 
$=52.3 \%$ ), and thus a random-effect model was applied. Results of this meta-analysis suggested that there was no significant association between the MDR1 rs1128503, rs1045642 and rs2032582 and MMR of CML patients (rs1045642 allele model: $\mathrm{OR}=0.917,95 \% \mathrm{Cl}=0.703-1.195, \mathrm{P}=0.520$, rs1128503 allele model: $\mathrm{OR}=1.043,95 \% \mathrm{Cl}=0.817-1.331, \mathrm{P}=0.737$, rs2032582 allele model: $\mathrm{OR}=1.167,95 \% \mathrm{Cl}=0.910-1.496, \mathrm{P}=0.223$, rs 1045642 dominant model: $\mathrm{OR}=1.005,95 \% \mathrm{Cl}$ $=0.657-1.536, \mathrm{P}=0.983, \mathrm{rs} 1128503$ dominant model: $\mathrm{OR}=1.102,95 \% \mathrm{Cl}=0.761-1.596, \mathrm{P}=$ 0.608, rs2032582 dominant model: $\mathrm{OR}=1.029,95 \% \mathrm{Cl}=0.677-1.562, \mathrm{P}=0.894, \mathrm{rs} 1045642$ homozygous model: $\mathrm{OR}=0.780,95 \% \mathrm{Cl}=0.360-1.689, \mathrm{P}=0.529, \mathrm{rs} 1128503$ homozygous model: $\mathrm{OR}=1.110,95 \% \mathrm{Cl}=0.418-2.943, \mathrm{P}=0.834, \mathrm{rs} 2032582$ homozygous model: $\mathrm{OR}=1.391,95 \% \mathrm{Cl}$ $=0.605-3.197, \mathrm{P}=0.438, \mathrm{rs} 1045642$ heterozygous model: $\mathrm{OR}=1.216,95 \% \mathrm{Cl}=0.728-2.033, \mathrm{P}=$ 0.455 , rs 1128503 heterozygous model: $\mathrm{OR}=0.822,95 \% \mathrm{Cl}=0.350-1.926, \mathrm{P}=0.651, \mathrm{rs} 2032582$ heterozygous model: $\mathrm{OR}=0.623,95 \% \mathrm{Cl}=0.275-1.410, \mathrm{P}=0.256$, rs 1045642 recessive model: $\mathrm{OR}=0.817,95 \% \mathrm{Cl}=0.499-1.337, \mathrm{P}=0.422, \mathrm{rs} 1128503$ recessive model: $\mathrm{OR}=1.215,95 \% \mathrm{Cl}=$ $0.557-2.654, \mathrm{P}=0.624$, rs2032582 recessive model: $\mathrm{OR}=1.473,95 \% \mathrm{Cl}=0.694-3.126, \mathrm{P}=0.313$ ) (Figure $2 \mathrm{~A}$ and $\mathrm{B}$ and Table 2).

\begin{tabular}{|c|c|c|c|c|c|c|c|c|c|}
\hline First author & Country & Number & Age (years) & Gender $(M / F)$ & Therapy & Treatment time & Response criteria & Genotyping method & SNP \\
\hline Vivona (2014) & Brazil & 28 & $52.8(30-68)$ & - & IM 400 mg/day & 60 months & MMR/CMR & qPCR & rs1128503 \\
\hline $\mathrm{Au}(2014)$ & Malaysia & 215 & $41.5(11-78)$ & $106 / 109$ & IM 400 mg/day & 6 months & MMR/Responsive & PCR-RFLP & $\begin{array}{l}\mathrm{rs} 1128503= \\
\mathrm{rs} 1045642= \\
\mathrm{rs} 2032582\end{array}$ \\
\hline Seong (2013) & Korea & 82 & $50(17-79)$ & $58 / 24$ & IM 400 mg/day & 6 months & MMR/CCyR & RT-PCR & $\begin{array}{l}\mathrm{rs} 1128503= \\
\mathrm{rs} 1045642\end{array}$ \\
\hline Elghannam (2013) & Egypt & 96 & $44.4 \pm 12.4$ & $54 / 42$ & IM 400-600 mg/day & 3-18 months & $\begin{array}{l}\text { MMR/CMR/CCyR/ } \\
\text { Responsive }\end{array}$ & RT-PCR & rs2032582 \\
\hline $\mathrm{Ni}$ (2011) & China & 52 & $44(18-76)$ & $33 / 19$ & IM 400 mg/day & 12 months & Responsive & PCR-RFLP & $\begin{array}{l}\text { rs } 1128503= \\
\text { rs1045642 }= \\
\text { rs2032582 }\end{array}$ \\
\hline Takahashi (2010) & Japan & 67 & $57.8(20-81)$ & $37 / 30$ & IM 300-400 mg/day & NA & MMR & PCR-RFLP & $\begin{array}{l}\text { rs1045642 = } \\
\text { rs2032582 }\end{array}$ \\
\hline Marin (2010) & UK & 87 & $45.4(20-86)$ & $49 / 38$ & IM 400 mg/day & 59.7 months & MMR/CMR & RT-PCR & rs1128503 \\
\hline $\operatorname{Kim}(2010)$ & Canada & 229 & $52.5(20-75)$ & $134 / 95$ & IM 400-800 mg/day & $12-18$ months & MMR/CMR & MassARRAY & $\begin{array}{l}\mathrm{rs} 1128503= \\
\mathrm{rs} 1045642= \\
\mathrm{rs} 2032582\end{array}$ \\
\hline Deenik (2010) & Nederland & 46 & - & - & IM 800 mg/day & 12 months & MMR/CMR & TaqManAssay & $\begin{array}{l}\text { rs1128503 }= \\
\text { rs1045642 = } \\
\text { rs2032582 }\end{array}$ \\
\hline Dulucq (2008) & France & 85 & $52.4 \pm 14.3$ & $53 / 32$ & IM 400 mg/day & 12 months & MMR & RT-PCR & rs1128503 \\
\hline
\end{tabular}

\section{Association between CMR to IM in CML patients and MDR1 polymorphisms}

We again found that no heterogeneity existed across the gene frequencies of CML patients (allele model: $\mathrm{P}=0.398, I^{2}=4.47 \%$, dominant model: $\mathrm{P}=0.855, I^{2}=0.00 \%$, homozygous model: $\mathrm{P}=0.380, I^{2}=6.44 \%$, heterozygous model: $\mathrm{P}=0.076, I^{2}=43.77 \%$, recessive model: $\mathrm{P}=0.194, I^{2}$ $=28.17 \%$ ), and thus a fixed-effect model was applied. Results of this meta-analysis suggested that there was no significant association between the MDR1 rs1128503, rs1045642, and rs2032582 and CMR of CML patients (rs1045642 allele model: $\mathrm{OR}=1.467,95 \% \mathrm{Cl}=0.807-2.664, \mathrm{P}=0.209$, rs1128503 allele model: $\mathrm{OR}=0.943,95 \% \mathrm{Cl}=0.681-1.305, \mathrm{P}=0.722$, rs2032582 allele model: $\mathrm{OR}=1.012,95 \% \mathrm{Cl}=0.670-1.529, \mathrm{P}=0.955, \mathrm{rs} 1045642$ dominant model: $\mathrm{OR}=0.777,95 \% \mathrm{Cl}$ 


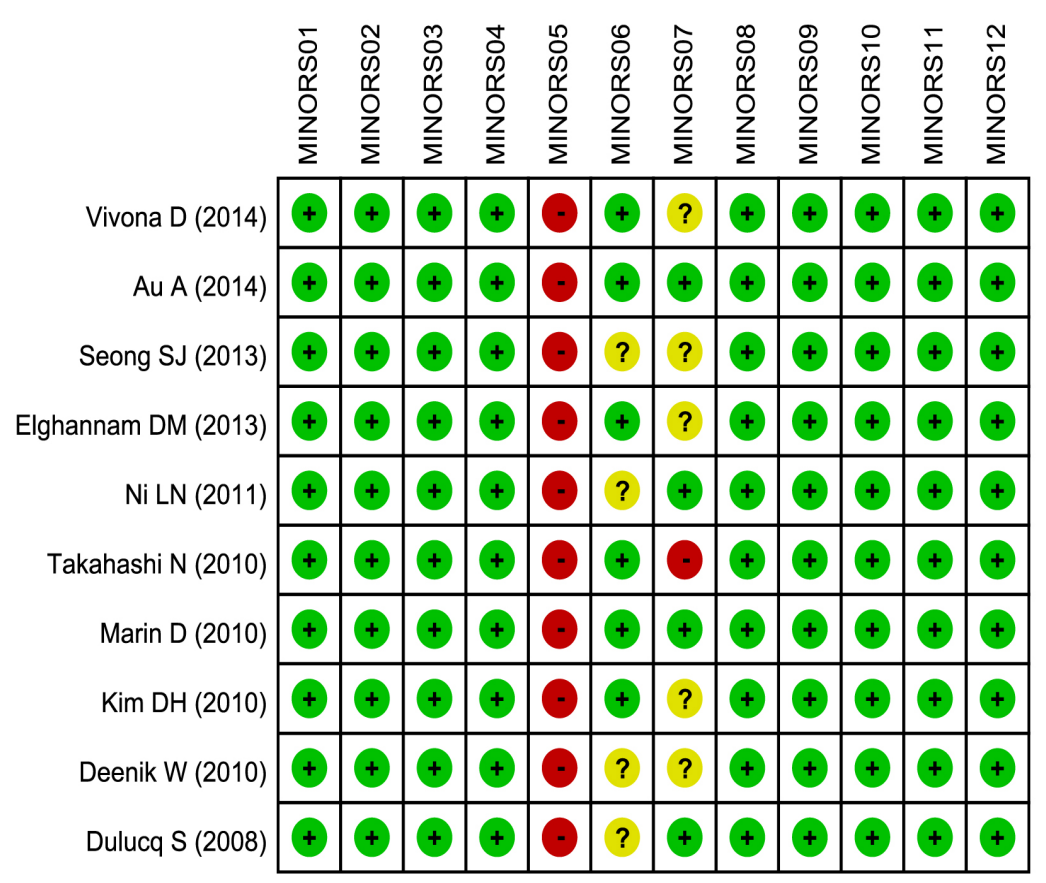

Figure 1. Evaluation of the methodological quality of all the enrolled studies via methodological index for nonrandomized studies.

\begin{tabular}{|c|c|c|c|c|c|c|c|c|c|c|c|}
\hline \multirow[t]{2}{*}{ Gene model } & & & \multicolumn{3}{|c|}{ MMR vs Non-MMR } & \multicolumn{3}{|c|}{ CMR vs Non-CMR } & \multicolumn{3}{|c|}{ Resistant vs Responsive } \\
\hline & & & OR & $95 \% \mathrm{Cl}$ & $P$ & OR & $95 \% \mathrm{Cl}$ & $\mathrm{P}$ & OR & $95 \% \mathrm{Cl}$ & $\mathrm{P}$ \\
\hline \multirow[t]{3}{*}{ M allele $v s \mathrm{~W}$ allele (Allele model) } & SNP & rs1045642 & 0.917 & 0.703-1.195 & 0.520 & 1.467 & $0.807-2.664$ & 0.209 & 1.586 & $0.515-4.877$ & 0.421 \\
\hline & & rs 1128503 & 1.043 & $0.817-1.331$ & 0.737 & 0.943 & $0.681-1.305$ & 0.722 & 2.411 & $0.982-5.921$ & 0.055 \\
\hline & & rs2032582 & 1.167 & $0.910-1.496$ & 0.223 & 1.012 & $0.670-1.529$ & 0.955 & 0.637 & $0.474-0.855$ & 0.003 \\
\hline \multirow[t]{3}{*}{ WM + MM vs WW (Dominant model) } & SNP & rs1045642 & 1.005 & $0.657-1.536$ & 0.983 & 0.777 & $0.294-2.055$ & 0.611 & 1.712 & $0.325-9.019$ & 0.526 \\
\hline & & rs 1128503 & 1.102 & $0.761-1.596$ & 0.608 & 0.862 & $0.525-1.417$ & 0.559 & 2.113 & $0.945-4.724$ & 0.068 \\
\hline & & rs2032582 & 1.029 & $0.677-1.562$ & 0.894 & 0.799 & $0.427-1.495$ & 0.483 & 0.827 & $0.505-1.354$ & 0.450 \\
\hline \multirow[t]{3}{*}{ MM vs WW (Homozygous model) } & SNP & rs 1045642 & 0.780 & $0.360-1.689$ & 0.529 & 1.634 & $0.383-6.967$ & 0.507 & 2.974 & $0.204-43.340$ & 0.425 \\
\hline & & rs1128503 & 1.110 & $0.418-2.943$ & 0.834 & 0.898 & $0.468-1.724$ & 0.746 & 4.647 & 1.773-12.177 & 0.002 \\
\hline & & rs2032582 & 1.391 & $0.605-3.197$ & 0.438 & 1.168 & $0.516-2.645$ & 0.709 & 0.349 & $0.182-0.670$ & 0.002 \\
\hline \multirow[t]{3}{*}{ MM vs WM (Heterozygous model) } & SNP & rs 1045642 & 1.216 & $0.728-2.033$ & 0.455 & 0.478 & $0.132-1.736$ & 0.262 & 0.707 & $0.329-1.518$ & 0.374 \\
\hline & & rs1128503 & 0.822 & $0.350-1.926$ & 0.651 & 0.954 & $0.532-1.711$ & 0.874 & 0.332 & $0.160-0.688$ & 0.003 \\
\hline & & rs2032582 & 0.623 & $0.275-1.410$ & 0.256 & 0.635 & $0.294-1.372$ & 0.248 & 3.308 & $1.835-5.967$ & $<0.001$ \\
\hline \multirow[t]{3}{*}{ MM vs WW + WM (Recessive model) } & SNP & rs 1045642 & 0.817 & $0.499-1.337$ & 0.422 & 1.766 & $0.520-5.998$ & 0.362 & 2.069 & $0.381-11.249$ & 0.400 \\
\hline & & rs 1128503 & 1.215 & $0.557-2.654$ & 0.624 & 0.994 & $0.579-1.706$ & 0.983 & 3.744 & $1.678-8.355$ & 0.001 \\
\hline & & rs2032582 & 1.473 & $0.694-3.126$ & 0.313 & 1.421 & $0.698-2.894$ & 0.333 & 0.331 & $0.193-0.568$ & $<0.001$ \\
\hline
\end{tabular}

$\mathrm{OR}=$ odds risk $; 95 \% \mathrm{Cl}=95 \%$ confidential intervals; $\mathrm{SNP}=$ single nucleotide polymorphism; $\mathrm{MMR}=$ major molecular response; $\mathrm{CMR}=$ complete molecular response. 
$=0.294-2.055, \mathrm{P}=0.611, \mathrm{rs} 1128503$ dominant model: $\mathrm{OR}=0.862,95 \% \mathrm{Cl}=0.525-1.417, \mathrm{P}=$ 0.559, rs2032582 dominant model: $\mathrm{OR}=0.799,95 \% \mathrm{Cl}=0.427-1.495, \mathrm{P}=0.483, \mathrm{rs} 1045642$ homozygous model: $\mathrm{OR}=1.634,95 \% \mathrm{Cl}=0.383-6.967, \mathrm{P}=0.507, \mathrm{rs} 1128503$ homozygous model: $\mathrm{OR}=0.898,95 \% \mathrm{Cl}=0.468-1.724, \mathrm{P}=0.746, \mathrm{rs} 2032582$ homozygous model: $\mathrm{OR}=1.168,95 \% \mathrm{Cl}$ $=0.516-2.645, \mathrm{P}=0.709$, rs 1045642 heterozygous model: $\mathrm{OR}=0.478,95 \% \mathrm{Cl}=0.132-1.736, \mathrm{P}=$ 0.262 , rs 1128503 heterozygous model: $\mathrm{OR}=0.954,95 \% \mathrm{Cl}=0.532-1.711, \mathrm{P}=0.874, \mathrm{rs} 2032582$ heterozygous model: $\mathrm{OR}=0.635,95 \% \mathrm{Cl}=0.294-1.372, \mathrm{P}=0.248, \mathrm{rs} 1045642$ recessive model: $\mathrm{OR}=1.766,95 \% \mathrm{Cl}=0.520-5.998, \mathrm{P}=0.362$, rs1128503 recessive model: $\mathrm{OR}=0.994,95 \% \mathrm{Cl}=$ $0.579-1.706, \mathrm{P}=0.983, \mathrm{rs} 2032582$ recessive model: $\mathrm{OR}=1.421,95 \% \mathrm{Cl}=0.698-2.894, \mathrm{P}=0.333$ ) (Figure 2C and D and Table 2).
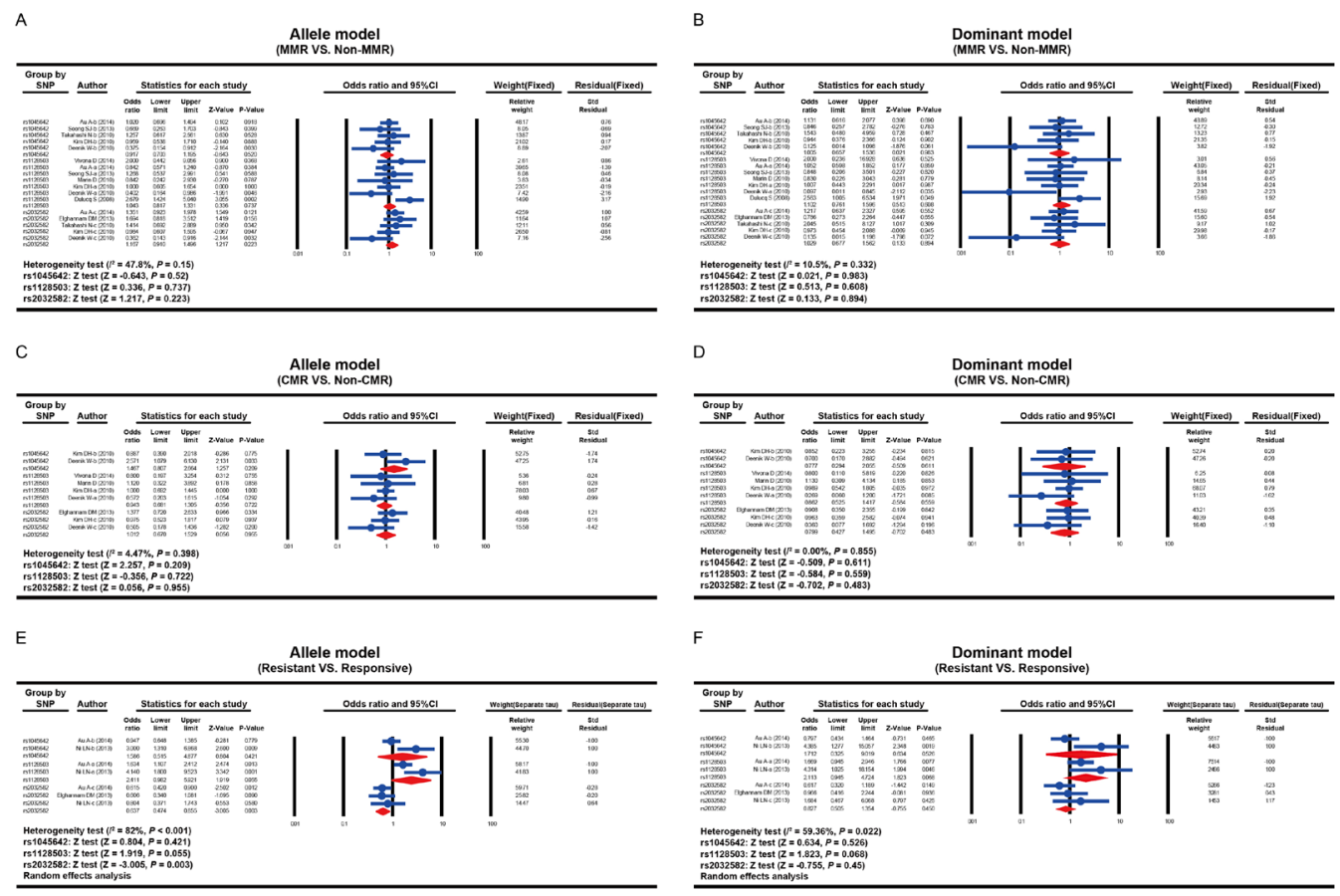

Figure 2. Forest plots of the correlations between the single nucleotide polymorphisms in MDR1 and response to imatinib in chronic myeloid leukemia patients.

\section{Association between resistance to IM in CML patients and MDR1 polymorphisms}

No heterogeneity existed across the gene frequencies of CML patients (allele model: $\mathrm{P}$ $=0.00, l^{2}=82.0 \%$, dominant model: $\mathrm{P}=0.022, l^{2}=59.36 \%$, homozygous model: $\mathrm{P}=0.00, l^{2}=$ 80.84\%, heterozygous model: $\mathrm{P}=0.00, l^{2}=79.76 \%$, recessive model: $\mathrm{P}=0.00, l^{2}=82.81 \%$ ), and thus a random-effect model was used. Results of this study demonstrated that there was no significant association between MDR1 rs1045642 polymorphism and resistance in CML patients (allele model: $\mathrm{OR}=1.586,95 \% \mathrm{Cl}=0.515-4.877, \mathrm{P}=0.421$, dominant model: $\mathrm{OR}=1.712,95 \% \mathrm{Cl}=0.325-9.019$, $\mathrm{P}=0.526$, homozygous model: $\mathrm{OR}=2.974,95 \% \mathrm{Cl}=0.204-43.340, \mathrm{P}=0.425$, heterozygous model: 
$\mathrm{OR}=0.707,95 \% \mathrm{Cl}=0.329-1.518, \mathrm{P}=0.374$, recessive model: $\mathrm{OR}=2.069,95 \% \mathrm{Cl}=0.381-11.249$, $\mathrm{P}=0.400$ ). Under homozygous, heterozygous and recessive models of MDR1 rs1128503, significant differences were observed in the genotype frequencies between $C M L$ patients sensitive to IM and those resistant to IM (homozygous model: $\mathrm{OR}=4.647,95 \% \mathrm{Cl}=1.773-12.177, \mathrm{P}=0.002$, heterozygous model: $\mathrm{OR}=0.332,95 \% \mathrm{Cl}=0.160-0.688, \mathrm{P}=0.003$, recessive model: $\mathrm{OR}=3.744,95 \% \mathrm{Cl}=1.678$ $8.355, \mathrm{P}=0.001$ ), while there was no significant correlation between MDR1rs1128503 polymorphism and resistance in CML patients under allele and dominant models (allele model: $\mathrm{OR}=2.411,95 \% \mathrm{Cl}=$ $0.982-5.921, \mathrm{P}=0.055$, dominant model: $\mathrm{OR}=2.113,95 \% \mathrm{Cl}=0.945-4.724, \mathrm{P}=0.068)$. A significant difference in the genotype frequencies of MDR1 rs2032582 under allele, homozygous, heterozygous, and recessive models was observed between $\mathrm{CML}$ patients sensitive and resistant to IM (allele model: $\mathrm{OR}=0.637,95 \% \mathrm{Cl}=0.474-0.855, \mathrm{P}=0.003$, homozygous model: $\mathrm{OR}=0.349,95 \% \mathrm{Cl}=0.182-0.670$, $\mathrm{P}=0.002$, heterozygous model: $\mathrm{OR}=3.308,95 \% \mathrm{Cl}=1.835-5.967, \mathrm{P}<0.001$, recessive model: OR $=0.331,95 \% \mathrm{Cl}=0.193-0.568, \mathrm{P}<0.001)$, while there was no significant correlation between MDR1 rs2032582 polymorphism and resistance in $\mathrm{CML}$ patients $(\mathrm{OR}=0.827,95 \% \mathrm{Cl}=0.505-1.354, \mathrm{P}=$ 0.450) (Figure 2E and F and Table 2).

\section{Sensitivity analysis and publication bias}

The result of the sensitivity analysis suggested there was no single study that influenced the pooled OR (Figure 3). The funnel plots of correlations between the MDR1 rs1128503, rs1045642, and rs2032582 polymorphisms and response to IM in CML patients were symmetric, suggesting that there was no significant publication bias. Classic fail-safe $\mathrm{N}$ and the Egger test further confirmed no publication bias (all P > 0.05) (Figure 4).

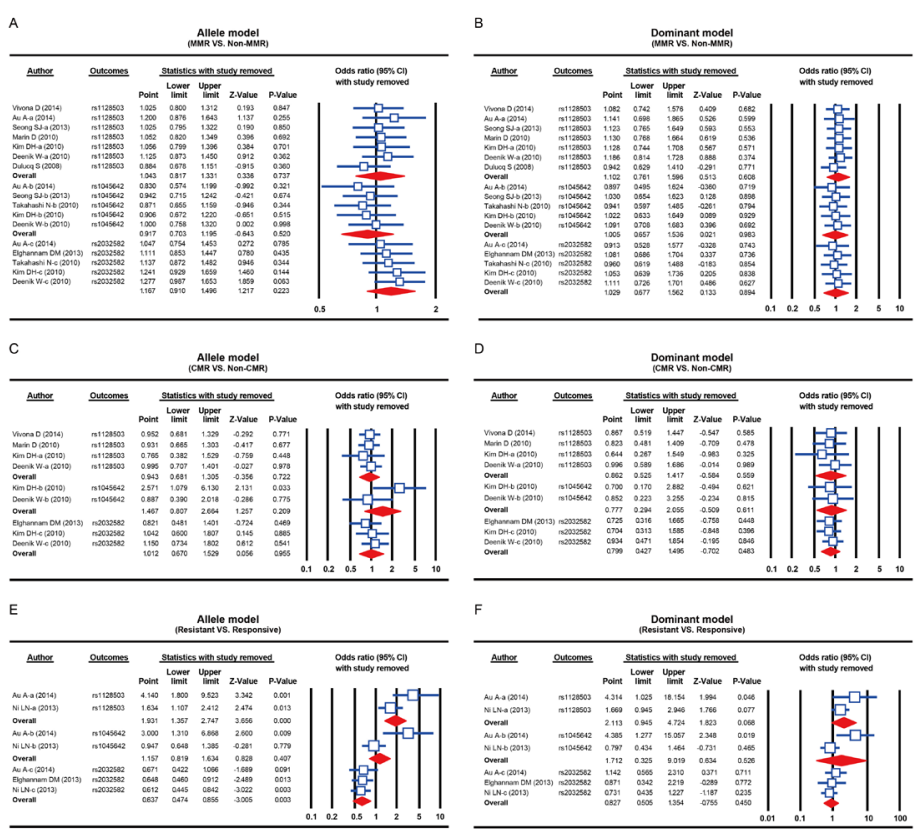

Figure 3. Results of sensitivity analysis on the correlations between the single nucleotide polymorphisms in MDR1 and response to imatinib in chronic myeloid leukemia patients. 
A

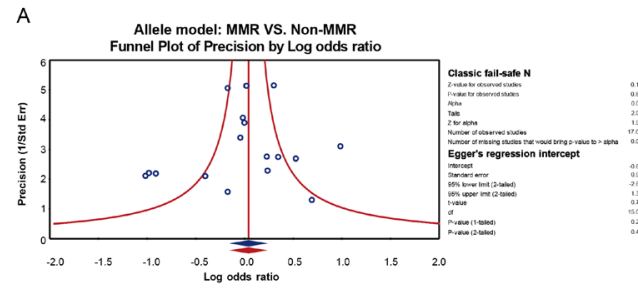

C

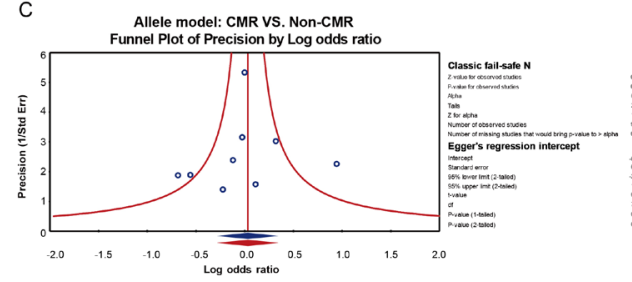

E

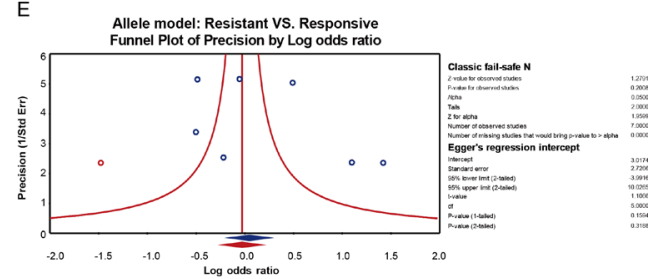

B
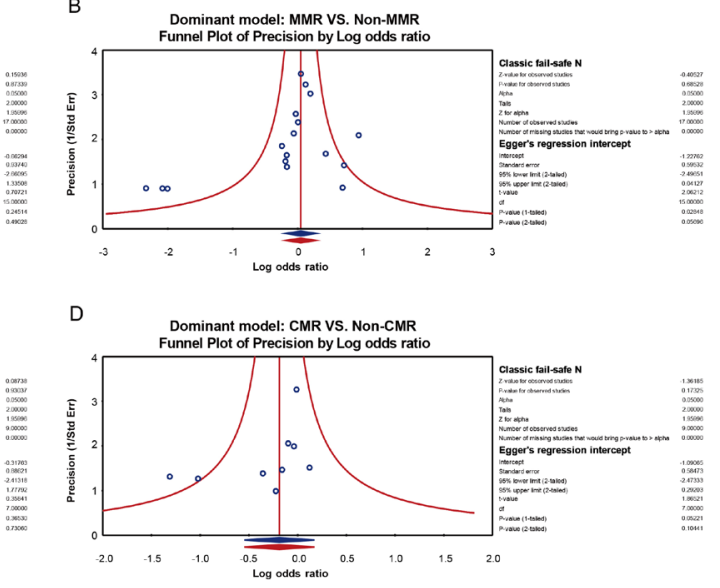

F Dominant model: Resistant vs. Responsive

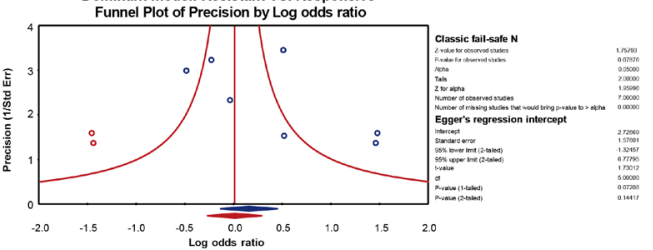

Figure 4. Funnel plots of the correlations between the single nucleotide polymorphisms in MDR1 and response to imatinib in chronic myeloid leukemia patients.

\section{DISCUSSION}

We investigated the correlation between MDR1 genetic polymorphisms and the response to IM, including MMR, CMR, and resistance in patients with CML, based on pooled data from previous studies. MMR is an important surrogate biomarker for prediction of long-term outcomes of IM treatment in CML. CMR has also been evaluated in clinical studies as a surrogate biomarker for prediction of the long-term outcome of IM therapy in CP-CML (Shinohara et al., 2013). European Leukemia Net defines CMR as BCR-ABL mRNA transcripts undetectable by qRT-PCR and/or nested PCR in two consecutive high-quality samples with sensitivity (Cross et al., 2012). Our results showed that MDR1 rs1128503, rs1045642, and rs2032582 polymorphisms had no significant association with the MMR and CMR in CML patients that received the IM therapy, which is contrary to a few previous studies that showed genetic variations in MDR1 influenced response to IM in CML patients (Seong et al., 2013; Vivona et al., 2014). This might be attributed to the obscure definition of $C M L$ and the doses of IM in the included studies. The enrolled patients with CML were in different phases. Optimization of the standard dosage of IM has been well established as $400 \mathrm{mg} /$ day. However, for CML patients in AP and BP, high doses of IM are more effective. One study also reported a more rapid remission by IM $800 \mathrm{mg} /$ day in patients with CP-CML (Hehlmann et al., 2011). Therefore, analysis of patients randomly assigned to high-dose IM in early CP-CML appears to be an appropriate next step. Among the enrolled patients, the patients with CP-CML received the therapy of IM $400 \mathrm{mg} /$ day. However, some studies had no strict definition on the CML 
and whether the doses of IM were satisfactory for patients to have the CMR or MMR, and thus, no significant association was observed between MDR1 rs1128503, rs1045642 and rs2032582 polymorphisms and MMR and CMR.

Results of the present meta-analysis also revealed that there were significant differences in the genotype frequencies of MDR1 rs1128503 and rs2032582 under different models between CML patients sensitive to IM and those resistant to IM, suggesting that the SNPS of MDR1 could influence the resistance to IM in patients with CML. P-gp, encoded by MDR1 gene, is an energy-dependent multidrug efflux pump mediating the efflux of IM (Diamond and Melo, 2011). Overexpression of P-gp confers resistance to IM in leukemia cell lines (Agrawal et al., 2014), and Pgp expressing cells had lower IM intracellular levels. SNPs have the potential to affect the expression and function of the P-gp, could also influence the efficiency of absorption or elimination of IM and could explain at least in part variable responses to this drug (Elghannam et al., 2014). Vivona et al. (2014) revealed a significant association between MDR1 haplotypes and P-gp activity in CML patients, which further supports our result. This result was also consistent with the result of study reported by B Zu et al. (2014), which suggested that MDR1 rs1128503 polymorphism was associated with the increasing risk of IM resistance in Asian CML patients.

There are some limitations in this meta-analysis. First, the relatively small sample size leads to a lack of uniformly strong statistical power. Second, inter-study heterogeneity still existed in this meta-analysis although we minimized the likelihood by performing a sensitive literature search strategy, using stringent inclusion and exclusion criteria. The differences include clinical parameters such as disease phase, disease duration, and the use of medication. Finally, several different outcome measures were used for IM therapy. Consequently, further study is warranted to comprehensively investigate the association of MDR1 polymorphisms and the MMR and CMR in CML patients.

In conclusion, we found that the MDR1 rs1128503, rs1045642, and rs2032582 polymorphisms had no significant association with the MMR and CMR in CML patients, therefore, we propose that the MDR1 polymorphisms are not directly associated with response to IM therapy in patients with CML. The specific effect of IM therapy in treatment of different-phase of CML is still not known fully, and future detailed studies are essential to further confirm the conclusions of our study.

\section{Conflicts of interest}

The authors declare no conflict of interest.

\section{ACKNOWLEDGMENTS}

We appreciate the reviewers who gave us precious comments on this paper.

\section{REFERENCES}

Agrawal M, Hanfstein B, Erben P, Wolf D, et al. (2014). MDR1 expression predicts outcome of $\mathrm{Ph}+$ chronic phase CML patients on second-line nilotinib therapy after imatinib failure. Leukemia 28: 1478-1485.

Au A, Aziz Baba A, Goh AS, Wahid Fadilah SA, et al. (2014). Association of genotypes and haplotypes of multi-drug transporter genes $A B C B 1$ and $A B C G 2$ with clinical response to imatinib mesylate in chronic myeloid leukemia patients. Biomed. Pharmacother. 68: 343-349.

Bilgi N, Bell K, Ananthakrishnan AN and Atallah E (2010). Imatinib and Panax ginseng: a potential interaction resulting in liver toxicity. Ann. Pharmacother. 44: 926-928.

Bodor M, Kelly EJ and Ho RJ (2005). Characterization of the human MDR1 gene. AAPS J. 7: E1-5. 
Chen H, Manning AK and Dupuis J (2012). A method of moments estimator for random effect multivariate meta-analysis. Biometrics 68: 1278-1284.

Cross NC, White HE, Muller MC, Saglio G, et al. (2012). Standardized definitions of molecular response in chronic myeloid leukemia. Leukemia 26: 2172-2175.

Deenik W, van der Holt B, Janssen JJ, Chu IW, et al. (2010). Polymorphisms in the multidrug resistance gene MDR1 (ABCB1) predict for molecular resistance in patients with newly diagnosed chronic myeloid leukemia receiving high-dose imatinib. Blood 116: 6144-6145; author reply 6145-6146.

Della Peruta M, Martinelli G, Moratti E, Pintani D, et al. (2010). Protein tyrosine phosphatase receptor type \{gamma\} is a functional tumor suppressor gene specifically downregulated in chronic myeloid leukemia. Cancer Res. 70: 8896-8906.

Diamond JM and Melo JV (2011). Mechanisms of resistance to BCR-ABL kinase inhibitors. Leuk. Lymphoma 52 (Suppl 1): $12-22$.

Dulucq S, Bouchet S, Turcq B, Lippert E, et al. (2008). Multidrug resistance gene (MDR1) polymorphisms are associated with major molecular responses to standard-dose imatinib in chronic myeloid leukemia. Blood 112: 2024-2027.

Egger M, Davey Smith G, Schneider M and Minder C (1997). Bias in meta-analysis detected by a simple, graphical test. BMJ 315: 629-634

Elghannam DM, Ibrahim L, Ebrahim MA, Azmy E, et al. (2013). Association of MDR1 gene polymorphism (G2677T) with imatinib response in Egyptian chronic myeloid leukemia patients. Hematology 19: 123-128.

Giannoudis A, Davies A, Harris RJ, Lucas CM, et al. (2014). The clinical significance of ABCC3 as an imatinib transporter in chronic myeloid leukaemia. Leukemia 28: 1360-1363.

Hehlmann R, Lauseker M, Jung-Munkwitz S, Leitner A, et al. (2011). Tolerability-adapted imatinib 800 mg/d versus 400 mg/d versus $400 \mathrm{mg} / \mathrm{d}$ plus interferon-alpha in newly diagnosed chronic myeloid leukemia. J. Clin. Oncol. 29: 1634-1642.

Hurtz C, Hatzi K, Cerchietti L, Braig M, et al. (2011). BCL6-mediated repression of p53 is critical for leukemia stem cell survival in chronic myeloid leukemia. J. Exp. Med. 208: 2163-2174.

Jabbour E and Kantarjian H (2012). Chronic myeloid leukemia: 2012 update on diagnosis, monitoring, and management. Am. J. Hematol. 87: 1037-1045.

Jabbour E, Cortes JE and Kantarjian HM (2009). Suboptimal response to or failure of imatinib treatment for chronic myeloid leukemia: what is the optimal strategy? Mayo Clin. Proc. 84: 161-169.

Jabbour E, Cortes J and Kantarjian H (2011). Long-term outcomes in the second-line treatment of chronic myeloid leukemia: a review of tyrosine kinase inhibitors. Cancer 117: 897-906.

Jackson D, White IR and Riley RD (2012). Quantifying the impact of between-study heterogeneity in multivariate metaanalyses. Stat. Med. 31: 3805-3820.

Kantarjian HM, Giles FJ, Bhalla KN, Pinilla-lbarz J, et al. (2011). Nilotinib is effective in patients with chronic myeloid leukemia in chronic phase after imatinib resistance or intolerance: 24-month follow-up results. Blood 117: 1141-1145.

Kim DH, Kong JH, Byeun JY, Jung CW, et al. (2010). The IFNG (IFN-gamma) genotype predicts cytogenetic and molecular response to imatinib therapy in chronic myeloid leukemia. Clin. Cancer Res. 16: 5339-5350.

Kurzawski M, Pawlik A, Gornik W and Drozdzik M (2006). Frequency of common MDR1 gene variants in a Polish population. Pharmacol. Rep. 58: 35-40.

Maffioli M, Camos M, Gaya A, Hernandez-Boluda JC, et al. (2011). Correlation between genetic polymorphisms of the hOCT1 and MDR1 genes and the response to imatinib in patients newly diagnosed with chronic-phase chronic myeloid leukemia. Leuk. Res. 35: 1014-1019.

Marin D, Bazeos A, Mahon FX, Eliasson L, et al. (2010). Adherence is the critical factor for achieving molecular responses in patients with chronic myeloid leukemia who achieve complete cytogenetic responses on imatinib. J. Clin. Oncol. 28: 2381-2388.

Ni LN, Li JY, Miao KR, Qiao C, et al. (2011). Multidrug resistance gene (MDR1) polymorphisms correlate with imatinib response in chronic myeloid leukemia. Med. Oncol. 28: 265-269.

O'Hare T, Zabriskie MS, Eiring AM and Deininger MW (2012). Pushing the limits of targeted therapy in chronic myeloid leukaemia. Nat. Rev. Cancer 12: 513-526.

Pavey T, Hoyle M, Ciani O, Crathorne L, et al. (2012). Dasatinib, nilotinib and standard-dose imatinib for the first-line treatment of chronic myeloid leukaemia: systematic reviews and economic analyses. Health Technol. Assess. 16: 1-277.

Perrotti D, Jamieson C, Goldman J and Skorski T (2010). Chronic myeloid leukemia: mechanisms of blastic transformation. J. Clin. Invest. 120: 2254-2264.

Peters JL, Sutton AJ, Jones DR, Abrams KR, et al. (2006). Comparison of two methods to detect publication bias in metaanalysis. JAMA 295: 676-680.

Seong SJ, Lim M, Sohn SK, Moon JH, et al. (2013). Influence of enzyme and transporter polymorphisms on trough imatinib concentration and clinical response in chronic myeloid leukemia patients. Ann. Oncol. 24: 756-760. 
Shinohara Y, Takahashi N, Nishiwaki K, Hino M, et al. (2013). A multicenter clinical study evaluating the confirmed complete molecular response rate in imatinib-treated patients with chronic phase chronic myeloid leukemia by using the international scale of real-time quantitative polymerase chain reaction. Haematologica 98: 1407-1413.

Slim K, Nini E, Forestier D, Kwiatkowski F, et al. (2003). Methodological index for non-randomized studies (minors): development and validation of a new instrument. ANZ. J. Surg. 73: 712-716.

Soverini S, Branford S, Nicolini FE, Talpaz M, et al. (2014). Implications of BCR-ABL1 kinase domain-mediated resistance in chronic myeloid leukemia. Leuk. Res. 38: 10-20.

Sterne JA and Egger M (2001). Funnel plots for detecting bias in meta-analysis: guidelines on choice of axis. J. Clin. Epidemiol. 54: 1046-1055.

Takahashi N, Miura M, Scott SA, Kagaya H, et al. (2010). Influence of CYP3A5 and drug transporter polymorphisms on imatinib trough concentration and clinical response among patients with chronic phase chronic myeloid leukemia. J. Hum. Genet. 55: 731-737.

Vasconcelos FC, Silva KL, Souza PS, Silva LF, et al. (2011). Variation of MDR proteins expression and activity levels according to clinical status and evolution of CML patients. Cytometry B Clin. Cytom. 80: 158-166.

Vivona D, Bueno CT, Lima LT, Hirata RD, et al. (2012). ABCB1 haplotype is associated with major molecular response in chronic myeloid leukemia patients treated with standard-dose of imatinib. Blood Cells Mol. Dis. 48: 132-136.

Vivona D, Lima LT, Rodrigues AC, Bueno CT, et al. (2014). ABCB1 haplotypes are associated with P-gp activity and affect a major molecular response in chronic myeloid leukemia patients treated with a standard dose of imatinib. Oncol. Lett. 7 : 1313-1319.

Wikstrom EA, Naik S, Lodha N and Cauraugh JH (2009). Balance capabilities after lateral ankle trauma and intervention: a meta-analysis. Med. Sci. Sports Exerc. 41: 1287-1295.

Zintzaras E and loannidis JP (2005). Heterogeneity testing in meta-analysis of genome searches. Genet. Epidemiol. 28: $123-137$.

Zu B, Li Y, Wang X, He D, et al. (2014). MDR1 gene polymorphisms and imatinib response in chronic myeloid leukemia: a meta-analysis. Pharmacogenomics 15: 667-677. 